\title{
Антимонопольный комплаенс как средство предупреждения коррупции в сфере осуществления государственных и муниципальных закупок
}

\author{
(C) Овчаров Артем Валерьевич, \\ кандидат юридических наук, научный сотрудник \\ сектора уголовного права, уголовного процесса и \\ криминологии ИГП РАН
}

\begin{abstract}
Аннотация. Статья посвящена рассмотрению и анализу такого нового для нашего государства правового явления, как комплаенс (система управления рисками), применительно к одному из его видов, а именно комплаенсу антимонопольному. Автором рассматривается понятие антимонопольного комплаенса, анализируется его содержание, значение и принципы построения. В статье анализируется взаимосвязь антикоррупционной и антимонополистической деятельности и делается вывод о необходимости рассмотрения антимонопольного комплаенса в качестве инструмента противодействия коррупции в сфере осуществления государственных закупок.

Ключевые слова: преступность, антимонопольная деятельность, коррупция, конкуренция, комплаенс, государство, экономика, национальная безопасность, преступление, государственные закупки.
\end{abstract}

\section{Antimonopoly compliance as a means of preventing corruption in the implementation of state and municipal procurement}

\section{(C) Ovcharov A. V.,}

$\mathrm{PhD}$ in Law, research fellow of sector of criminal law, criminal proceeding and criminology of the Institute of State and Law of RAS,

\begin{abstract}
The article is devoted to the consideration and analysis of such a new legal phenomenon for our state as compliance (risk management system), in addition to one of its types, namely antitrust compliance. The author considers the concept of antimonopoly compliance, analyzes its content, meaning and principles of construction. The article analyzes the relationship between anti-corruption and antimonopoly activities and concludes that it is necessary to consider antimonopoly compliance as a tool for combating corruption in the field of public procurement.

Keywords: crime, antimonopoly activity, corruption, competition, compliance, state, economy, national security, crime, public procurement.
\end{abstract}

В научной литературе не раз отмечалось, что современное состояние преступности в нашей стране является угрозой национальной безопасности России, что обуславливает потребность формирования государством адекватной уголовной политики противодействия преступности ${ }^{1}$.

\footnotetext{
1 Преступность в XXI веке. Приоритетные направления противодействия : монография / под общ. ред. чл.-корр. РАН А. Н. Савенкова. М.: ЮНИТИ-ДАНА : Закон и право, 2020. С. 9.
}

Уголовная политика любого государства должна охватывать противодействие всем видам преступности, в том числе и преступности коррупционной, как одного из наиболее опасных видов преступных проявлений, посягающего на нормальное функционирование всей совокупности органов государственной власти и местного самоуправления. В этой связи следует сказать, что предупреждение преступности как система мер, предпринимаемых государственными органами, общественными 
организациями, представителями власти и другими лицами, направленных на противодействие процессам детерминизации преступности, имеющих целью ресоциализацию потенциальных преступников, предотвращение совершения новых преступлений, в целом является одним из наиболее эффективных средств противодействия самой преступности в целом и преступности коррупционной в частности.

Следует сразу же отметить, что негативному явлению коррупции в той или иной мере подвержена система любой власти, однако традиционно существуют более или менее коррупционные сферы. Так, сфера осуществления закупок для государственных и муниципальных нужд традиционно является одной из наиболее коррупционных сфер экономической деятельности, а потому представляется, что борьба с коррупцией в рассматриваемой сфере имеет первостепенное значение ${ }^{1}$.

Так, еще в Указе Президента Российской Федерации от 29 июня 2018 г. № 378 «О Национальном плане противодействия коррупции на 2018-2020 годы» совершенствованию мер по противодействию коррупции в сфере закупок товаров, работ, услуг для обеспечения государственных или муниципальных нужд и в сфере закупок товаров, работ, услуг отдельными видами юридических лиц был посвящен отдельный раздел ${ }^{2}$.

Предупреждение коррупции в сфере осуществления закупок - это многоаспектная деятельность, но она тесно взаимосвязана с предупреждением монополизации рынка. Монополизация всегда связана с коррупцией и симбиоз этих явлений порождает устранение свободного конкурентного рыночного ценообразования и

\footnotetext{
1 Корякин В. М. Противодействие коррупции в сфере государственных закупок для нужд обороны и военной безопасности : монография. М.: Юрлитинформ, 2014; Овчаров А. В. Уголовная ответственность за злоупотребления в сфере осуществления государственного оборонного заказа // Военное право. 2019. № 6 (58).

2 Овчаров А.В. Уголовная ответственность в сфере осуществления государственных закупок как новелла Российского уголовного законодательства // Военное право. 2019. № 2 (54). С. 257.
}

устанавливают власть над ценами. Любая монополия, являясь единственным продавцом на рынке, имеет возможность управлять ценой по своему разумению, и это зачастую идет вразрез с интересами общества.

Политика противодействия коррупции всегда теснейшим образом связана с мерами антимонопольной политики. И антикоррупционная, и антимонополистическая деятельность имеют общие цели и сходные регуляторы. При различных условиях возникает значительное число факторов взаимовлияния инструментов антикоррупционной и антимонопольной политики.

В научной литературе отмечалось, что международный опыт эмпирической проверки направления и силы взаимосвязи между коррупцией и конкуренцией позволяет выявить двустороннюю причинноследственную связь. С одной стороны, низкий уровень развития конкуренции ведет к росту коррупционной активности, а с другой - высокий уровень коррупции, в свою очередь, является причиной снижения индикаторов конкуренции ${ }^{3}$.

УК РФ содержит ст. 178, которая предусматривает ответственность за ограничение конкуренции путем заключения хозяйствующими субъектамиконкурентами ограничивающего конкуренцию соглашения (картеля), запрещенного в соответствии с антимонопольным законодательством Российской Федерации, если это деяние причинило крупный ущерб гражданам, организациям или государству либо повлекло извлечение дохода в крупном размере. При определенных обстоятельствах данное преступление может быть отнесено к преступлениям коррупционной направленности.

В связи с тем, что нормы рассматриваемой статьи бланкетные, установление признаков состава преступления должно осуществляться с учетом нормативно-

\footnotetext{
3 Мелешкина А. И. Факторы, определяющие характер взаимосвязи коррупции и конкуренции: обзор эмпирических исследований // Вестник Московского университета. Серия 6. Экономика. Московский государственный университет им. М. В. Ломоносова. 2017. № 6. С. 94.
} 
правовых актов в сфере защиты конкуренции.

Существующая система антимонопольного регулирования включает в себя Федеральный закон «О защите конкуренции», который конкретизирует положения рассматриваемой статьи (определение терминов «картель», «доминирующее положение на рынке» и т.д.), и целый ряд приказов и иных нормативно-правовых документов, разработанных Правительством Российской Федерации и антимонопольным органом, которые конкретизируют и дополняют федеральное законодательство.

Исходя из особой важности антимонопольной деятельности, Указом Президента Российской Федерации от 21 декабря 2017 г. № 618 «Об основных направлениях государственной политики по развитию конкуренции» определены цели и основополагающие принципы государственной политики по развитию конкуренции. Данный указ провозглашает, что целях укрепления национальной экономики, дальнейшего развития конкуренции и недопущения монополистической деятельности активное содействие развитию конкуренции в Российской Федерации следует считать приоритетным направлением деятельности Президента Российской Федерации, Федерального Собрания Российской Федерации, Правительства Российской Федерации, Центрального банка Российской Федерации, федеральных органов исполнительной власти, законодательных (представительных) и исполнительных органов государственной власти субъектов Российской Федерации, а также органов местного самоуправления. Исходя из анализа текста рассматриваемого указа, можно сделать вывод, что он определяет целый спектр направлений деятельности, направленных на развитие конкуренции. Они могут быть определены следующим образом:

1) повышение удовлетворенности потребителей за счет расширения ассортимента товаров, работ, услуг, повышения их качества и снижения цен;

2) повышение экономической эффективности и конкурентоспособности хозяйствующих субъектов, в том числе за счет обеспечения равного доступа к товарам и услугам субъектов естественных монополий и государственным услугам, необходимым для ведения предпринимательской деятельности, стимулирования инновационной активности хозяйствующих субъектов, повышения доли наукоемких товаров и услуг в структуре производства, развития рынков высокотехнологичной продукции;

3) стабильный рост и развитие многоукладной экономики, развитие технологий, снижение издержек в масштабе национальной экономики, снижение социальной напряженности в обществе, обеспечение национальной безопасности;

4) сокращение доли хозяйствующих субъектов, учреждаемых или контролируемых государством или муниципальными образованиями, в общем количестве хозяйствующих субъектов, осуществляющих деятельность на товарных рынках;

5) обеспечение равных условий и свободы экономической деятельности на территории Российской Федерации;

6) обеспечение развития малого и среднего предпринимательства;

7) направленность государственных инвестиций на развитие конкуренции;

8) обеспечение условий для привлечения инвестиций хозяйствующих субъектов в развитие товарных рынков;

9) недопустимость сдерживания экономически оправданного перехода сфер естественных монополий из состояния естественной монополии в состояние конкурентного рынка;

10) государственное регулирование цен (тарифов), основанное на окупаемости организаций, осуществляющих регулируемые виды деятельности, при снижении издержек и повышении их эффективности, обеспечивающее интересы потребителей в долгосрочной перспективе;

11) недопустимость государственного регулирования цен (тарифов), осуществляемого посредством определения (установления) цен (тарифов) или их предельного уровня на конкурентных товарных рынках, за исключением случаев, предусмотренных законодательством Российской Федерации; 
12) развитие конкуренции в сферах экономической деятельности государственных предприятий, предприятий с государственным участием;

13) сочетание превентивного и последующего контроля для целей защиты конкуренции;

14) стимулирование хозяйствующих субъектов, в том числе занимающих доминирующее положение на товарных рынках, внедряющих систему внутреннего обеспечения соответствия требованиям антимонопольного законодательства;

15) открытость антимонопольной политики;

16) ответственность органов государственной власти и органов местного самоуправления за реализацию государственной политики по развитию конкуренции;

17) измеримость результатов государственной политики по развитию конкуренции;

18) стимулирование со стороны государства добросовестных практик осуществления хозяйственной деятельности;

19) развитие организованной (биржевой) торговли в Российской Федерации;

20) информационная открытость деятельности инфраструктурных монополий;

21) обеспечение прозрачности закупок товаров, работ, услуг для государственных и муниципальных нужд, а также закупок товаров, работ и услуг инфраструктурными монополиями и компаниями с государственным участием;

22) внедрение риск-ориентированного подхода в деятельности органов государственного контроля (надзора);

23) совершенствование антимонопольного регулирования в условиях развития цифровой экономики и ее глобализации в целях эффективного пресечения нарушений антимонопольного законодательства, носящих трансграничный характер, и повышения конкурентоспособности российских компаний на мировых рынках.

Вместе с тем, рассматриваемый Указ устанавливает запреты на введение или сохранение ограничений, создающих дискриминационные условия в отношении отдельных видов экономической деятельности, производства и оборота отдельных видов товаров, оказания отдельных видов услуг, за исключением случаев, предусмотренных федеральными законами, правовыми актами Президента Российской Федерации, правовыми актами Правительства Российской Федерации и на необоснованное вмешательство в свободное функционирование товарных рынков, издание актов, принятие решений, которые могут привести к недопущению, устранению конкуренции.

Кроме того, Указом утвержден Национальный план развития конкуренции в Российской Федерации на 2018-2020 годы. Согласно п. 2 данного плана Правительству Российской Федерации было поручено до 1 марта 2019 г. принять меры, направленные на создание и организацию системы внутреннего обеспечения соответствия требованиям антимонопольного законодательства деятельности федеральных органов исполнительной власти.

Распоряжением Правительства Российской Федерации от 16 августа 2018 г. № 1697-р утвержден План мероприятий («дорожная карта») по развитию конкуренции в отраслях экономики Российской Федерации и переходу отдельных сфер естественных монополий из состояния естественной монополии в состояние конкурентного рынка на 2018-2020 годы. В соответствии с п. 3 указанного распоряжения руководителям федеральных органов исполнительной власти было поручено по согласованию с ФАС России до 1 декабря 2018 г. принять правовые акты об организации системы внутреннего обеспечения соответствия требованиям антимонопольного законодательства, а также обеспечить принятие системы подведомственными организациями.

Распоряжением Правительства Российской Федерации от 18 октября 2018 г. № 2258-р утверждены методические рекомендации по созданию и организации федеральными органами исполнительной власти системы внутреннего обеспечения соответствия требованиям антимонопольного законодательства, а также установлены требования к содержанию Системы (антимонопольного комплаенса). 
Что же из себя представляет антимонопольный комплаенс?

Любой комплаенс - это определенная система соответствия каким-либо внутренним или внешним требованиям и нормам. Основополагающим актом для любой системы соответствия является Международный стандарт ISO 19600 Системы управления соответствием. Руководящие указания (Compliance management systems - Guidelines).

Антимонопольный комплаенс представляет собой систему внутреннего обеспечения соответствия требованиям антимонопольного законодательства. Любое отклонение от соответствия есть риски. Можно сказать, что риски нарушения антимонопольного законодательства представляют собой сочетание вероятности и последствий наступления неблагоприятных событий в виде ограничения, устранения или недопущения конкуренции.

Целями создания антимонопольного комплаенса являются, с одной стороны, обеспечение соответствия деятельности федерального органа исполнительной власти требованиям антимонопольного законодательства, а с другой - профилактика нарушения требований антимонопольного законодательства в деятельности федерального органа исполнительной власти.

Задачами антимонопольного комплаенса являются:

1) выявление рисков нарушения антимонопольного законодательства;

2) управление рисками нарушения антимонопольного законодательства;

3) контроль за соответствием деятельности федерального органа исполнительной власти требованиям антимонопольного законодательства;

4) оценка эффективности функционирования в федеральном органе исполнительной власти антимонопольного комплаенса.

При создании антимонопольного комплаенса любой федеральный орган исполнительной власти должен руководствоваться определенными принципами. Данные принципы определяются следующим образом. Это:
1) заинтересованность руководства федерального органа исполнительной власти в эффективности функционирования антимонопольного комплаенса;

2) регулярность оценки рисков нарушения антимонопольного законодательства;

3) обеспечение информационной открытости функционирования в федеральном органе исполнительной власти антимонопольного комплаенса;

4) непрерывность функционирования антимонопольного комплаенса в федеральном органе исполнительной власти;

5) совершенствование антимонопольного комплаенса.

Конечно же, основной задачей создания антимонопольного комплаенса является выявление и оценка рисков нарушения антимонопольного законодательства. В этих целях уполномоченным подразделением или должностным лицом органа исполнительной власти на регулярной основе должны проводиться определенные мероприятия.

Прежде всего, это анализ выявленных нарушений антимонопольного законодательства в деятельности федерального органа исполнительной власти за предыдущие 3 года (наличие предостережений, предупреждений, штрафов, жалоб, возбужденных дел). При проведении не реже одного раза в год такого анализа должно быть реализовано следующее:

1) осуществление сбора в структурных подразделениях и территориальных органах федерального органа исполнительной власти сведений о наличии нарушений антимонопольного законодательства;

2) составление перечня нарушений антимонопольного законодательства в федеральном органе исполнительной власти, который содержит классифицированные по сферам деятельности федерального органа исполнительной власти сведения о выявленных за последние 3 года нарушениях антимонопольного законодательства (отдельно по каждому нарушению) и информацию о нарушении (указание нарушенной нормы антимонопольного законодательства, краткое изложение сути нарушения, указание последствий нарушения 
антимонопольного законодательства и результата рассмотрения нарушения антимонопольным органом), позицию антимонопольного органа, сведения о мерах по устранению нарушения, а также о мерах, направленных федеральным органом исполнительной власти на недопущение повторения нарушения.

Второй группой мероприятий является анализ нормативных правовых актов федерального органа исполнительной власти на предмет выявления возможных случаев нарушения антимонопольного законодательства. При проведении не реже одного раза в год такого анализа должны реализовываться следующие мероприятия:

1) разработка и размещение на официальном сайте исчерпывающего перечня нормативных правовых актов федерального органа исполнительной власти с приложением к перечню актов текстов таких актов, за исключением актов, содержащих сведения, относящиеся к охраняемой законом тайне;

2) размещение на официальном сайте уведомления о начале сбора замечаний и предложений организаций и граждан по перечню актов;

3) осуществление сбора и проведение анализа представленных замечаний и предложений организаций и граждан по перечню актов;

4) представление руководству федерального органа исполнительной власти сводного доклада с обоснованием целесообразности (нецелесообразности) внесения изменений в нормативные правовые акты федерального органа исполнительной власти.

Вместе с тем необходимо проводить и анализ проектов нормативных правовых актов федерального органа исполнительной власти на предмет выявления возможных случаев нарушения антимонопольного законодательства. В рамках этой деятельности реализуется следующее:

1) размещение на официальном сайте (размещение на официальном сайте regulation.gov.ru в информационнотелекоммуникационной сети "Интернет" приравнивается к такому размещению) проекта нормативного правового акта с необходимым обоснованием реализации предлагаемых решений, в том числе их влияния на конкуренцию;

2) осуществление сбора и проведение оценки поступивших от организаций и граждан замечаний и предложений по проекту нормативного правового акта.

Третьим направлением деятельности любого органа исполнительной власти по недопущению нарушений антимонопольного законодательства является мониторинг и анализ практики применения федеральным органом исполнительной власти антимонопольного законодательства. В рамках такой деятельности необходимо осуществление следующего:

1) осуществление на постоянной основе сбора сведений о правоприменительной практике в федеральном органе исполнительной власти;

2) подготовка по итогам сбора информации аналитической справки об изменениях и основных аспектах правоприменительной практики в федеральном органе исполнительной власти;

3) проведение не реже одного раза в год рабочих совещаний с приглашением представителей антимонопольного органа по обсуждению результатов правоприменительной практики в федеральном органе исполнительной власти.

Последним направлением деятельности является проведение систематической оценки эффективности разработанных и реализуемых мероприятий по снижению рисков нарушения антимонопольного законодательства. При выявлении рисков нарушения антимонопольного законодательства уполномоченным подразделением или должностным лицом должна проводиться оценка таких рисков с учетом следующих показателей:

1) отрицательное влияние на отношение институтов гражданского общества к деятельности федерального органа исполнительной власти по развитию конкуренции;

2) выдача предупреждения о прекращении действий (бездействия), которые содержат признаки нарушения антимонопольного законодательства; 
3) возбуждение дела о нарушении антимонопольного законодательства;

4) привлечение к административной ответственности в виде наложения штрафов на должностных лиц или в виде их дисквалификации.

В случае обнаружения рисков нарушения антимонопольного законодательства в целях их снижения, уполномоченным подразделением или должностным лицом любого органа власти должны разрабатываться не реже одного раза в год мероприятия по снижению рисков нарушения антимонопольного законодательства. Необходимо осуществлять постоянный мониторинг исполнения мероприятий по снижению рисков нарушения антимонопольного законодательства. Информация об исполнении мероприятий по снижению рисков нарушения антимонопольного законодательства должна включаться в доклад об антимонопольном комплаенсе. Таковы общие положения об антимонопольном комплаенсе.

Представляется, что наличие в органе исполнительной власти антимонопольного комплаенса, ориентированного на специфику деятельности и особенности того или иного органа власти будет являться эффективным инструментом противодействия монополизации рынка, а как следствие, поскольку монополизация неразрывно связана с коррупцией и инструментом противодействия коррупции, прежде всего в сфере, где опасность ограничения конкуренции наиболее высока, а именно в сфере осуществления государственных и муниципальных закупок.

\section{Библиография}

1. Корякин, В. М. Противодействие коррупции в сфере государственных закупок для нужд обороны и военной безопасности : монография / В. М. Корякин. - М.: Юрлитинформ, 2014.

2. Мелешкина, А. И. Факторы, определяющие характер взаимосвязи коррупции и конкуренции: обзор эмпирических исследований / А. И. Мелешкина // Вестник Московского университета. Серия 6. Экономика. Московский государственный университет им. М. В. Ломоносова. — 2017. — № 6.

3. Овчаров, А. В. Уголовная ответственность в сфере осуществления государственных закупок как новелла Российского уголовного законодательства / А. В. Овчаров // Военное право. - 2019. — № 2 (54).

4. Овчаров, А.В. Уголовная ответственность за злоупотребления в сфере осуществления государственного оборонного заказа / А. В. Овчаров // Военное право. — 2019. — № 6 (58).

5. Преступность в XXI веке. Приоритетные направления противодействия : монография / под общ. ред. чл.-корр. РАН А. Н. Савенкова. - М.: ЮНИТИ-ДАНА : Закон и право, 2020. 